\title{
Resfriamento artificial na conservação da qualidade comercial de grãos de milho armazenados
}

\author{
José Ronaldo Quirino $\left({ }^{(*)}\right.$; Aniela Pilar Campos de Melo $\left({ }^{2}\right)$; Valquíria da Rocha Santos Veloso ( ${ }^{2}$; \\ Karina Cordeiro Albernaz $\left({ }^{2}\right)$; Jaqueline Magalhães Pereira $\left({ }^{2}\right)$ \\ (') Caramuru Alimentos S/A, 75900-000 Rio Verde (GO), Brasil \\ (2) Universidade Federal de Goiás (UFG), Campus Samambaia, 74690-900 Goiânia (GO), Brasil \\ $\left({ }^{*}\right)$ Autor correspondente: zeronaldo@caramuru.com
}

Recebido: 25/Mar./2013; Aceito: 25/Nov./2013

\section{Resumo}

O resfriamento artificial é uma ferramenta para conservação da qualidade de grãos nas regiões tropicais. Este trabalho foi realizado com o propósito de verificar o efeito da refrigeração artificial do ar, por meio de aeração, na preservação da qualidade de grãos de milho em armazém graneleiro horizontal, de fundo "V". Para o experimento foram utilizados dois septos, sendo um resfriado artificialmente $\left(12^{\circ} \mathrm{C}\right)$, com capacidade de 28 mil toneladas, e o outro aerado com ar natural, com capacidade de 29 mil toneladas. As amostragens foram realizadas, em ambos os septos, durante a carga, aos 60 e 120 dias após a primeira etapa de resfriamento e durante a expedição dos grãos. Durante o armazenamento, as amostragens foram realizadas considerando-se a posição e a profundidade da massa de grãos de milho. A avaliação qualitativa consistiu na determinação dos seguintes parâmetros: peso de mil grãos, temperatura da massa de grãos, teor e acidez de óleo, identificação de fungos, teor de aflatoxina, índice de infestação de insetos e porcentagem de grãos infestados. O resfriamento artificial promoveu a diminuição da temperatura da massa de grãos, independentemente das condições de temperatura e umidade do ar externo. A aeração artificial, com ar frio, preservou os parâmetros atribuídos à qualidade dos grãos e proporcionou redução na percentagem de grãos infestados e na população de insetos-praga na massa do produto. Assim, a utilização do resfriamento artificial no armazenamento de grãos de milho em regiões tropicais é eficaz na manutenção da qualidade dos grãos e no manejo de insetos e patógenos.

Palavras-chave: armazenamento, insecta, refrigeração, Zea mays.

\section{Artificial cooling on the conservation of commercial quality of stored maize grains}

\begin{abstract}
Artificial cooling is a tool used in the conservation of grain quality in tropical regions. In this study, we aimed to verify the effect of artificial cooling through aeration in preserving the quality of corn grains in bottom horizontal " $V$ " warehouses. Two septa were used in the experiment: an artificially cooled $\left(12^{\circ} \mathrm{C}\right)$ septum with capacity of 28 thousand tons and a naturally aerated septum with capacity of 29 thousand tons. Sampling was carried out in both septa during loading, at 60 and 120 days after the first stage of cooling, and during expedition. During storage, sampling was performed considering the position and depth of the corn mass. A qualitative assessment was conducted to determine the following parameters: weight of thousand grains, grain mass temperature, oil content and acidity, identification of fungi, aflatoxin content, insect infestation rate, and percentage of infested grain. Artificial cooling temperature promoted a decrease in grain mass, regardless of the external conditions of air temperature and humidity. Artificial aeration, with cold air, preserved the parameters assigned to grain quality and provided reduced percentage of infested grain and reduced population of insect pests in the product mass. Therefore, the use of artificial cooling in the storage of maize grains in tropical regions is effective in maintaining grain quality and managing insects and pathogens.
\end{abstract}

Key words: cooling, insecta, storage, Zea mays.

\section{INTRODUÇÃO}

O Brasil é o terceiro maior produtor de milho do mundo, superado apenas pelos Estados Unidos e China (FAO, 2013). Apesar de toda a capacidade produtiva brasileira, ressalta-se que as práticas realizadas da colheita ao armazenamento interferem, diretamente, na qualidade dos grãos (ALvEs et al., 2001; Dowdy e Mcgaughey, 1998; Gregori et al.,
2013; Herron et al., 1996; Marks e Stroshine, 1995; Vowotor et al., 1995; Rajarammanna et al., 2010).

$\mathrm{O}$ armazenamento propicia a manutenção das características qualitativas dos grãos, observadas depois da secagem, durante períodos prolongados de tempo. Contudo, nas regiôes tropicais ou subtropicais, alta temperatura e umidade relativa favorecem o desenvolvimento de insetospraga que infestam os grãos armazenados, causando perdas quantitativas, como a reduçáo de peso e/ou volume, e 
prejuízos qualitativos que culminam em contaminaçóes e diminuição do valor nutricional (BRACCINI e Picanço, 1995; White, 1992).

Os insetos-praga são a primeira causa de perda total em armazéns, em todo o mundo (Scussel, 2002; White et al., 1992). Os principais insetos-praga de grãos e de seus derivados industriais armazenados pertencem às ordens Coleoptera e Lepidoptera. Os danos causados durante o armazenamento podem equivaler, ou mesmo superar, aqueles provocados por pragas que infestam as culturas no campo, pois a deterioração nos grãos é definitiva e irreversível (Fontes et al., 2003).

De acordo com Aro (2008), a maioria dos insetos-praga de grãos armazenados é de origem tropical e subtropical, necessitando de temperaturas altas, na faixa de $27^{\circ} \mathrm{C}$ a $34^{\circ} \mathrm{C}$ para seu desenvolvimento completo. Entretanto, esse desenvolvimento pode ser retardado ou paralisado se a temperatura frequentemente ficar abaixo de $16^{\circ} \mathrm{C}$ (NAKAKITA e Ikenaga, 1997; Puzzi, 2000; Sun e Woods, 1997). Em regiôes frias, as populaçóes atingem níveis tâo baixos que não chegam a caracterizarem-se como pragas. Assim, o resfriamento artificial de grãos revela-se uma ferramenta importante a ser utilizada no manejo de insetos-praga em regiôes onde, devido ao clima, a aeração natural tem uso restrito (LASSERAN, 1981; White, 1992), apresentando também a vantagem de poder ser aplicado com eficiência em larga escala, otimizando o controle químico e retardando o surgimento de resistência (BECKETT, 2011; Eliopoulos et al., 2011; Fields e Korunic, 2000; Lazzari et al., 2006; LongStafF, 1997; Sun e Woods, 1997).

$\mathrm{Na}$ Austrália, Europa e Japão, o resfriamento artificial é utilizado como uma das principais técnicas para o manejo de insetos-praga na massa de grãos armazenados (Driscoll et al., 2000; NaKakita e Ikenaga, 1997). No Brasil, por ser uma técnica de disponibilidade recente, existem poucas informaçóes sobre a sua aplicação e vantagens técnicas e econômicas.

Com base no exposto, objetivou-se com este trabalho verificar o efeito do resfriamento artificial do ar de aeração sobre a preservação da qualidade comercial de grãos de milho e a sua relação com a infestação de insetos-praga e patógenos em armazém graneleiro horizontal.

\section{MATERIAL E MÉTODOS}

\section{Características do armazém}

A unidade armazenadora localiza-se em Jataí, Goiás. O armazém utilizado para o estudo é composto por três septos, com capacidade total de 90 mil toneladas. Utilizaram-se dois septos do armazém, o central, com capacidade de 28 mil toneladas, com resfriamento artificial, denominado septo resfriado, e outro, com capacidade armazenadora de 29 mil toneladas, aerado com ar natural e denominado septo aerado.

$\mathrm{O}$ ar resfriado foi insuflado no septo por meio de conexáo direta entre o equipamento resfriador e os dutos de concreto construídos no piso do armazém, feita por tubulaçóes confeccionadas em lona térmica impermeável e material plástico (polipropileno). $\mathrm{O}$ ar frio foi insuflado simultaneamente por dois dutos, no perfil de temperatura desejado. Depois a conexáo foi feita em outros pares de dutos, até que o perfil de temperatura de resfriamento desejado fosse atingido em toda a massa. A temperatura do ar na saída do equipamento foi de $12^{\circ} \mathrm{C}$. A operação de resfriamento foi realizadas em duas etapas, sendo a primeira de julho a setembro e a segunda, de outubro a dezembro.

No septo aerado, o processo foi conduzido utilizando-se os procedimentos operacionais da unidade armazenadora, atendendo normas técnicas, por meio de ventiladores centrífugos que insuflaram ar ambiente nos períodos mais frios do dia. Nesse septo, a insuflação do ar foi realizada por dutos laterais, velendo-se de quatro ventiladores.

Em ambos os septos, a distribuiçáo do ar na massa de milho foi feita por meio de casamatas, dispostas no fundo do armazém, sobre o túnel de descarga. Antes de iniciar o processo de aeraçáo e de resfriamento, foi desfeito o pico da massa formado pelo talude natural dos grãos.

\section{Amostragens}

Recepção: Os grãos de milho (colhidos na safrinha) foram armazenados com umidade entre $13 \%$ e $14 \%$ (b.u.), no mês de julho.

Armazenamento: Durante o armazenamento, duas amostragens de grãos (2.500 kg/septo) foram realizadas, sendo uma no final do primeiro ciclo de resfriamento (setembro) e a outra imediatamente após o segundo ciclo de resfriamento (novembro). No planejamento amostral, durante o armazenamento, os septos foram divididos em setores. Dentro dos setores foram estabelecidas posiçóes e para a mesma posição foram definidas diferentes profundidades, considerando-se a espessura da camada de produto.

Tanto o septo aerado quanto o resfriado foram divididos em três setores e cada setor foi considerado uma repetiçáo (Figura 1a). No primeiro e segundo setores de cada septo foram estabelecidos quatro pontos de amostragem e, no terceiro, três pontos de amostragem, como ilustrado na Figura 1b. Em cada ponto, com auxílio de uma sonda composta por tubos articulados conectados em um sistema pneumático para a sucção do produto, foi colhida uma amostra, em diferentes profundidades, divididas em superficial, intermediária e profunda (Figura 1a). Entretanto, devido ao formato do armazém não foi possível amostrar as três profundidades em todas as posiçóes definidas, como ilustrado na Figura 1a. As amostras compostas foram homogeneizadas e divididas no aparelho Boerner e em seguida acondicionadas em sacos de 


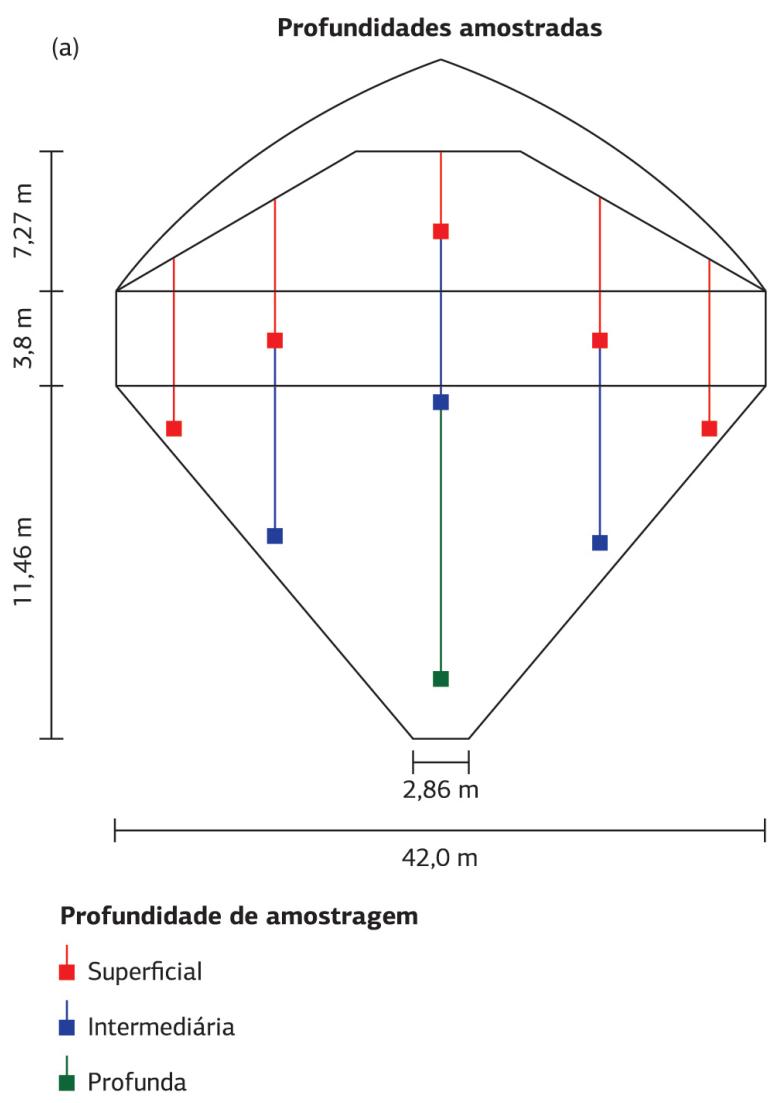

(b)

Posições amostradas
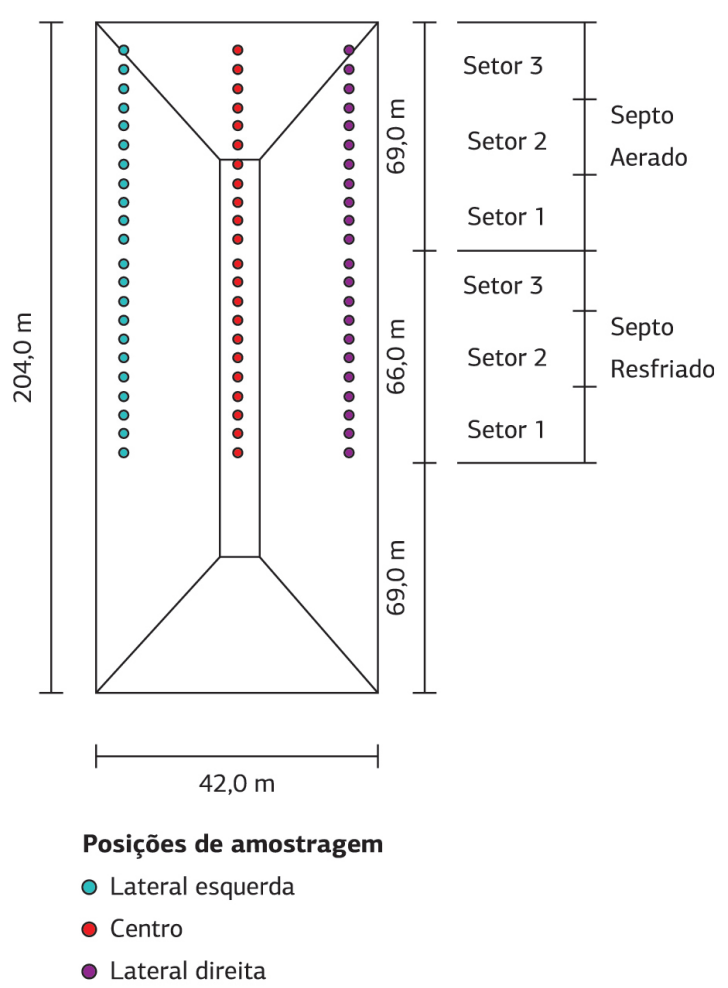

Figura 1. Croqui: esquema de amostragem no graneleiro durante o armazenamento indicando profundidades (a), posiçóes e setores (b).

papel, envoltas por sacos plásticos, lacradas e identificadas de acordo com a posiçáo e profundidade da coleta.

Expedição: Para coletar as amostras no final do período de armazenagem (etapa de expedição), adotaram-se os mesmos procedimentos executados durante a etapa de carregamento do armazém.

\section{Análises laboratoriais}

Durante a recepção e expedição foram avaliados: 1) Índice de insetos; 2) Porcentagem de grãos infestados; 3) Peso de mil grãos; e 4) Teor e acidez de óleo.

Durante o armazenamento, as avaliaçôes consistiram em: 1) Índice de insetos; 2) Porcentagem de grãos infestados; 3) Identificação de fungos e presença de micotoxinas (aflatoxina); 4) Peso de mil grãos; 5) Teor de óleo e acidez; e 6) Temperatura e umidade da massa de grãos.

O monitoramento da temperatura da massa de gráos nos septos resfriado e aerado foi realizado diariamente por meio de equipamento de termometria (Fockink, Air Master). Para as posiçôes amostradas, as temperaturas foram registradas semanalmente após o início do ciclo de resfriamento.

A determinação do teor de água nos grãos (umidade) e do peso de mil grãos foi realizada conforme BrAsIL (1992).
Para a quantificação do teor e acidez do óleo usaram-se os procedimentos AOCS Bc 3-49 e AOCS Ca 5a-40, respectivamente (Aocs, 1998). A identificação de fungos foi realizada conforme Dhingra e Sinclair (1996). Os teores de aflatoxina foram determinados por meio da técnica ELISA associada à cromatografia de afinidade (coluna de imunoafinidade por fluorimetria direta).

O cálculo da porcentagem de grãos infestados foi feito conforme Gallo et al. (2002). O índice de insetos foi calculado por meio do número de insetos vivos por quilograma de amostra. Para a determinação do índice, as impurezas foram retiradas das amostras e, com auxílio de uma lupa de 10 vezes de aumento, foi realizada a contagem e identificação dos insetos vivos (Gallo et al., 2002).

\section{Análise estatística}

O delineamento experimental utilizado foi inteiramente casualizado. As análises estatísticas foram efetuadas por meio de análise da variância (Teste F) e pelo teste de Tukey $(\mathrm{p}<0,05)$ para as variáveis estudadas - dados de septos, posiçôes, profundidades e para o estudo de interação entre septo e posição e septo e profundidade. 


\section{RESULTADOS E DISCUSSÃO}

\section{Recepção}

Os grãos de milho dos septos resfriado e aerado, na entrada do armazém, não apresentaram diferença $(p<0,05)$ em relaçáo ao peso de mil grãos (PMG), teor de óleo (TO), percentagem de grãos infestados (GI) e índice de insetos (II). Entretanto, houve diferença no teor de acidez de óleo (AO) entre septos (Tabela 1). Esse resultado demonstra equivalência qualitativa entre os materiais experimentais, embora estejam compatíveis com a exigência da Agência Nacional de Vigilância Sanitária (BrasiL, 2000), que fixa teor máximo de $3 \%$ de acidez dos grãos para a produção do óleo bruto de milho.

\section{Armazenamento}

Nos dois períodos de amostragem, independentemente do septo, não houve diferença entre as posições para todas as variáveis avaliadas. Esperava-se que algumas posiçôes fossem mais propícias ao desenvolvimento de insetos, devido à formação de microclimas (SANTOS, 2002) e à própria capacidade de migraçáo do inseto na massa de grãos (DowDy e Mcgaughey, 1998). Esse comportamento pode ser atribuído à uniformidade na temperatura da massa de grãos, em função da distribuição do ar, que acarretou a estabilidade térmica no interior do armazém.

As interaçóes entre os fatores (septo x profundidade) ocorreram para as variáveis: temperatura de grãos, peso de mil grãos e grãos infestados. As demais variáveis foram analisadas considerando-se as médias de cada fator, dentro de cada amostragem.

A evolução da temperatura dos grãos durante o período de armazenamento, dentro de cada septo, está apresentada na Figura 2. Observa-se que as temperaturas dos septos resfriado e aerado se mantiveram semelhantes até por volta do dia 31 de julho e que a partir dessa data as temperaturas diferenciaram-se, permanecendo sempre mais baixas no septo resfriado. A média durante o armazenamento para o septo resfriado foi de $17,6^{\circ} \mathrm{C}$ e. para o septo aerado, de $23,6^{\circ} \mathrm{C}$. Verificou-se que houve aumento da temperatura dos grãos no septo aerado durante o período de armazenagem, cuja temperatura inicial média, durante a primeira amostragem, foi de $20,9^{\circ} \mathrm{C}$ e, na segunda, de $26,3^{\circ} \mathrm{C}$.

As médias das temperaturas no septo resfriado se mantiveram estáveis nas duas amostragens, entre $17,3^{\circ} \mathrm{C}$ e

Tabela 1. Resultados médios do peso de mil grãos (PMG), teor de óleo (TO), acidez do óleo (AO), percentagem de grãos infestados (GI) e índice de insetos (II) dos grãos de milho durante o recebimento nos septos resfriado e aerado

\begin{tabular}{|c|c|c|c|c|c|}
\hline \multirow{2}{*}{ Septo } & \multicolumn{5}{|c|}{ Variáveis } \\
\hline & PMG & TO & AO & GI & II \\
\hline Resfriado & 308,92 a & $4,63 a$ & $2,32 \mathrm{~b}$ & $0,33 a$ & $0,00 \mathrm{a}$ \\
\hline Aerado & $304,04 \mathrm{a}$ & $4,44 \mathrm{a}$ & $2,88 \mathrm{a}$ & $0,17 \mathrm{a}$ & $0,00 \mathrm{a}$ \\
\hline
\end{tabular}

Médias seguidas por letras minúsculas iguais na mesma coluna não diferem entre si pelo teste de Tukey a 5\% de probabilidade

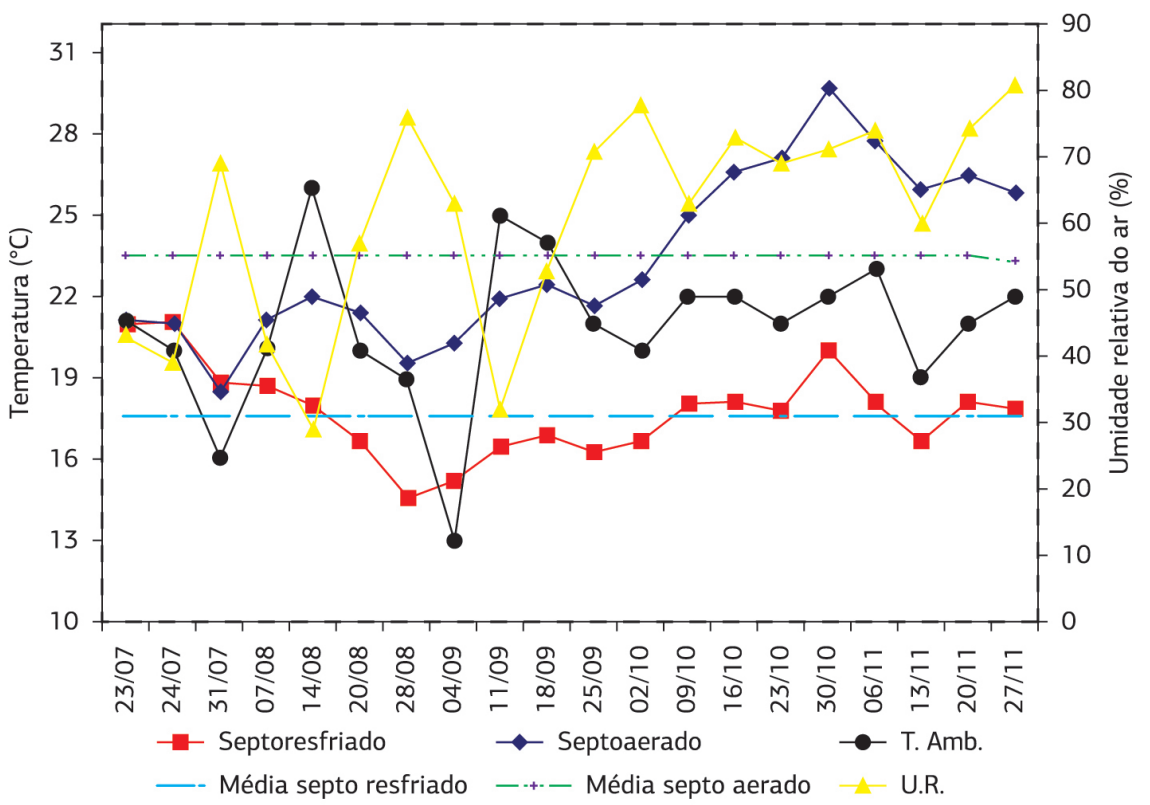

Figura 2. Evolução da temperatura $\left({ }^{\circ} \mathrm{C}\right)$ da massa de grãos nos septos resfriado e aerado, da temperatura ambiente e da umidade relativa do ar ambiente e médias de temperatura nos septos resfriado e aerado durante o período de armazenamento - julho a novembro. 
$17,9^{\circ} \mathrm{C}$. Garcia et al. (2000) e Navarro e Noyes (2002) relatam que em temperaturas abaixo de $20^{\circ} \mathrm{C}$ o crescimento de insetos em gráos armazenados é suprimido e que temperaturas entre $17^{\circ} \mathrm{C}$ e $22^{\circ} \mathrm{C}$ são consideradas seguras para reduzir o desenvolvimento de insetos-praga.

Em relação à interação entre os fatores septo e profundidade, não houve variação de temperatura no septo aerado nas profundidades e períodos amostrados (Tabela 2). Já no septo resfriado as temperaturas médias foram maiores nas camadas superficiais. Observou-se, portanto, que o aquecimento da massa de grãos ocorreu de cima para baixo, como já constatado por Volk e Afonso (2009). Esse comportamento pode ser atribuído ao calor proveniente da cobertura do armazém e conduzido para superfície da massa de grãos por meio de irradiação e convecção (JiA et al., 2001; LASSERAN, 1981). Nas camadas mais profundas a temperatura média equilibrou-se, pois os grãos uma vez resfriados aquecem muito lentamente em razão de sua baixa condutividade térmica (Elias, 2002; Lasseran, 1981; Santos, 2002).

Entre os septos aerado e resfriado não ocorreram diferenças no peso de mil grãos, conforme visto anteriormente. Entretanto, foi constatada variação dentro dos septos para essa variável (Tabela 3). Essa variação de peso pode estar associada à origem dos materiais armazenados (Evans, 1983; Lukow et al., 1995; Marks e Stroshine, 1995). No septo resfriado havia grãos remanescentes da safra anterior, mais especificamente, de safra de verão, nas camadas mais profundas, o que conferiu o maior peso na segunda amostragem. O mesmo ocorreu para o septo aerado. No entanto, ressalta-se que essas pequenas variaçóes não afetaram a conservação dos grãos, pois não houve a formação de bolsões de calor devido a migraçáo de umidade. Transferência de calor e de massa são fenômenos que podem ser observados durante o armazenamento (CARRERA-Rodríguez et al., 2011) e que podem propiciar perdas de massa seca pela respiraçáo dos grãos e de microrganismos associados.

$\mathrm{Na}$ primeira amostragem houve interação entre os fatores septo e profundidade para a variável grãos infestados. No septo resfriado, mesmo com os grãos em temperaturas mais baixas que no septo aerado, houve maior infestação, principalmente na profundidade intermediária (Tabela 4). Isso pode ter acontecido por a massa de grãos ter-se esfriado de baixo para cima e esse resfriamento mais lento na camada intermediária pode não ter prejudicado a alimentação e a reprodução dos insetos-praga durante esse intervalo de tempo.

$\mathrm{Na}$ segunda amostragem, a infestação de insetospraga foi substancialmente menor no septo resfriado em comparação com o aerado (Tabela 4), evidenciando a eficácia do resfriamento artificial na contenção da infestação de insetos nos gráos. Resultados semelhantes também foram observados por Eliopoulos et al. (2011); NAKakita e Ikenaga (1997) e Sun e Woods (1997).

$\mathrm{O}$ teor de óleo dos grãos não foi influenciado pelas condiçóes de armazenamento relacionadas a temperatura e profundidade. As condiçôes de conservação, em ambos os sistemas, proporcionaram a estabilidade no teor de óleo nas duas amostragens.

Em relação à avaliação de acidez do óleo houve diferença entre os septos na primeira amostragem. A acidez do óleo

Tabela 2. Média de temperaturas dos grâos $\left({ }^{\circ} \mathrm{C}\right)$ na primeira e na segunda amostragem, de acordo com a profundidade amostrada

\begin{tabular}{lcccc} 
& \multicolumn{2}{c}{ Septo resfriado } & \multicolumn{2}{c}{ Septo aerado } \\
\cline { 2 - 5 } Profundidade & Primeira amostragem & Segunda amostragem & Primeira amostragem & Segunda amostragem \\
\hline Superficial & $18,56 \mathrm{a}$ & $19,13 \mathrm{a}$ & $21,10 \mathrm{a}$ & $25,94 \mathrm{a}$ \\
Intermediária & $15,93 \mathrm{~b}$ & $16,32 \mathrm{~b}$ & $20,36 \mathrm{a}$ & $26,64 \mathrm{a}$ \\
\hline Profunda & $15,00 \mathrm{~b}$ & $16,73 \mathrm{ab}$ & $21,60 \mathrm{a}$ & $27,13 \mathrm{a}$ \\
\hline
\end{tabular}

Médias seguidas por letras minúsculas iguais na mesma coluna năo diferem entre si pelo teste de Tukey a $5 \%$ de significância

Tabela 3. Dados médios de peso de mil grãos (g) na primeira e na segunda amostragem, de acordo com a profundidade

\begin{tabular}{lcccc} 
& \multicolumn{2}{c}{ Septo resfriado } & \multicolumn{2}{c}{ Septo aerado } \\
\cline { 2 - 5 } Profundidade & Primeira amostragem & Segunda amostragem & Primeira amostragem & Segunda amostragem \\
\hline Superficial & $304,91 \mathrm{a}$ & $303,01 \mathrm{~b}$ & $307,56 \mathrm{ab}$ & $308,05 \mathrm{a}$ \\
\hline Intermediária & $303,74 \mathrm{a}$ & $309,22 \mathrm{ab}$ & $310,33 \mathrm{a}$ & $307,80 \mathrm{ab}$ \\
\hline Profunda & $313,70 \mathrm{a}$ & $315,80 \mathrm{a}$ & $299,97 \mathrm{~b}$ & $300,22 \mathrm{~b}$ \\
\hline
\end{tabular}

Médias seguidas por letras minúsculas iguais na mesma coluna não diferem entre si pelo teste de Tukey a 5\% de significância

Tabela 4. Grãos infestados (\%) na primeira amostragem nos septos resfriado e aerado, de acordo com as profundidades especificadas

\begin{tabular}{|c|c|c|c|c|}
\hline \multirow{2}{*}{ Profundidade } & \multicolumn{2}{|c|}{ Septo resfriado } & \multicolumn{2}{|c|}{ Septo aerado } \\
\hline & Primeira amostragem & Segunda amostragem & Primeira amostragem & Segunda amostragem \\
\hline Superficial & $1,40 \mathrm{~b}$ & $0,87 \mathrm{a}$ & $2,20 \mathrm{a}$ & $2,20 \mathrm{a}$ \\
\hline Intermediária & $2,89 \mathrm{a}$ & $0,89 \mathrm{a}$ & $0,94 \mathrm{a}$ & $1,94 \mathrm{a}$ \\
\hline Profunda & $1,67 \mathrm{ab}$ & $0,17 \mathrm{a}$ & $2,33 \mathrm{a}$ & $1,33 \mathrm{a}$ \\
\hline
\end{tabular}

Médias seguidas por letras minúsculas iguais na mesma coluna não diferem entre si pelo teste de Tukey a 5\% de significância 
no septo resfriado foi de $2,82 \%$, enquanto no septo aerado foi de $2,32 \%$. Essa diferença possivelmente ocorreu devido à estabilizaçáo da temperatura ocorrer apenas na camada superficial do septo resfriado e também pela influência da presença de grãos de safra anterior, conforme relatado anteriormente.

Baseado nos dados de evolução da contaminação fúngica, houve diferença entre as duas amostragens (Tabela 5). Na primeira amostragem no septo aerado, a colonização de Aspergilus flavus ocorreu de forma mais acentuada no centro, nas profundidades de 3,6 $\mathrm{m}$ a $8,4 \mathrm{~m}$ (UR $=13,5 \%$; temperatura $\left.=26,6^{\circ} \mathrm{C}\right)$ e abaixo de $8,4 \mathrm{~m}(\mathrm{UR}=13,2 \%$; temperatura $=27,13^{\circ} \mathrm{C}$ ). NAVArro et al. (2002) relata que a plena germinação de esporos de $A$. flavus ocorre em grãos de milho com teor de água de $16 \%$ a $17 \%$ (b.u.) e temperatura de $28^{\circ} \mathrm{C}$. Entấo essa colonização observada pode ser proveniente da contaminação nos campos de produçáo de grãos, nas moegas ou nos silos pulmôes. No entanto, para afirmaçóes seguras deve-se considerar a interação de vários fatores ligados ao ambiente de armazenamento, como umidade, temperatura, tempo, insetos-praga, nível de oxigênio e grau de infestação do fungo (ABramson et al., 2005; UdoH et al., 2000).

$\mathrm{Na}$ segunda amostragem não se verificou, em nenhum dos septos, colonização fúngica intensa nos grãos. As condiçôes de temperatura no armazenamento juntamente com a baixa umidade dos grãos podem ter contribuído para o baixo crescimento fúngico na massa de grãos.

Conforme os resultados apresentados na Tabela 6, no septo aerado não foi detectada aflatoxina nos grãos armazenados. Já no septo resfriado, o teor máximo de aflatoxina foi de $1 \mathrm{mg} \mathrm{L}^{-1}$, principalmente na parte central do septo. Esse valor é insignificante, considerando que o nível admitido para grãos de milho destinados à fabricação de alimentos prontos para oferta ao consumidor é de 20 ppb (Anvisa, 2011), de 300 ppb para grãos de milho utilizados para raçấo de bovinos de corte em fase de acabamento, de $200 \mathrm{ppb}$ para grãos de milho utilizados para ração de suínos em acabamento e de 100 ppb para grãos de milho utilizados em ração de suínos e aves adultos (Anvisa, 2002).

A presença de espécies potencialmente produtoras de aflatoxinas como, por exemplo, A. flavus (KLICH, 2007; Liu et al., 2006), encontradas no presente trabalho, não implicou necessariamente na detecção de aflatoxinas nas amostragens analisadas. Esses resultados sugerem que as espécies aflatoxigênicas não tiveram condiçôes favoráveis para a produçáo de aflatoxinas (DAvid Miller, 1995).

As espécies de insetos-praga encontradas durante o armazenamento e na expedição foram: Cryptolestes ferrugineus, Tribolium castaneum, Sitophilus zeamais, Oryzaephilus surinamensis, em ambos os septos, e Alphitobius diaperinus, somente no septo resfriado. A sobrevivência em baixas

Tabela 5. Determinação da colonização interna de grãos de milho por espécies de Aspergillus que colonizam os grãos secos armazenados nas amostras de entrada, primeira e segunda amostragem nos septos resfriado e aerado (\% de grãos colonizados/espécie)

\begin{tabular}{|c|c|c|c|c|c|c|c|c|}
\hline \multirow{3}{*}{ Setor/profundidade } & \multicolumn{4}{|c|}{ Primeira amostragem } & \multicolumn{4}{|c|}{ Segunda amostragem } \\
\hline & \multicolumn{4}{|c|}{ Fungos } & \multicolumn{4}{|c|}{ Fungos } \\
\hline & $\begin{array}{c}A . \\
\text { restrictus }\end{array}$ & $\begin{array}{c}\text { A. } \\
\text { glaucus }\end{array}$ & $\begin{array}{c}\text { A. } \\
\text { flavus }\end{array}$ & $\begin{array}{c}\text { Rhizopus } \\
\text { sp. }\end{array}$ & $\begin{array}{c}A . \\
\text { restrictus }\end{array}$ & $\begin{array}{c}\text { A. } \\
\text { glaucus }\end{array}$ & $\begin{array}{c}\text { A. } \\
\text { flavus }\end{array}$ & $\begin{array}{c}\text { Rhizopus } \\
\text { sp. }\end{array}$ \\
\hline \multicolumn{9}{|c|}{ Septo resfriado } \\
\hline Entrada & 26 & 7 & 2 & 0 & - & - & - & - \\
\hline Lado esquerdo & 28 & 49 & 0 & 0 & 2 & 3 & 1 & 0 \\
\hline Intermediária esquerda até 10 m & 11 & 3 & 1 & 0 & 5 & 0 & 0 & 0 \\
\hline Intermediária esquerda abaixo de 10 m & 9 & 7 & 3 & 3 & 10 & 3 & 13 & 3 \\
\hline Centro até 3,6 m & 4 & 7 & 0 & 0 & 1 & 6 & 2 & 2 \\
\hline Centro 3,6 m-8,4 m & 6 & 5 & 4 & 0 & 5 & 0 & 1 & 0 \\
\hline Centro abaixo de $8,4 \mathrm{~m}$ & 6 & 8 & 7 & 0 & 12 & 5 & 6 & 3 \\
\hline Intermediária direita até $10 \mathrm{~m}$ & 14 & 2 & 1 & 1 & 6 & 3 & 1 & 0 \\
\hline Intermediária direita abaixo de 10 m & 14 & 3 & 3 & 0 & 2 & 0 & 0 & 0 \\
\hline Lado direito & 8 & 3 & 3 & 0 & 7 & 2 & 1 & 0 \\
\hline \multicolumn{9}{|c|}{ Septo aerado } \\
\hline Entrada & 14 & 8 & 0 & 0 & - & - & - & - \\
\hline Lado esquerdo & 9 & 23 & 5 & 0 & 7 & 27 & 1 & 0 \\
\hline Intermediária esquerda até 10 m & 5 & 4 & 0 & 0 & 1 & 3 & 0 & 1 \\
\hline Intermediária esquerda abaixo de 10 m & 7 & 7 & 1 & 0 & 1 & 1 & 0 & 0 \\
\hline Centro até 3,6 m & 3 & 2 & 7 & 0 & 3 & 3 & 0 & 1 \\
\hline Centro 3,6 m-8,4 m & 3 & 8 & 25 & 3 & 2 & 0 & 0 & 0 \\
\hline Centro abaixo de $8,4 \mathrm{~m}$ & 0 & 11 & 69 & 0 & 2 & 2 & 0 & 0 \\
\hline Intermediária direita até 10 m & 1 & 4 & 6 & 0 & 11 & 2 & 1 & 0 \\
\hline Intermediária direita abaixo de 10 m & 2 & 4 & 8 & 1 & 5 & 2 & 1 & 5 \\
\hline Lado direito & 3 & 3 & 5 & 0 & 3 & 5 & 2 & 0 \\
\hline
\end{tabular}


Tabela 6. Concentração de aflatoxina $\left(\mathrm{mg} \mathrm{L}^{-1}\right)$ do milho na entrada para o armazenamento, na primeira e segunda amostragens e na expedição

\begin{tabular}{|c|c|c|c|c|}
\hline \multirow{2}{*}{ Posição } & \multicolumn{2}{|c|}{ Septo resfriado } & \multicolumn{2}{|c|}{ Septo aerado } \\
\hline & Primeira amostragem & Segunda amostragem & Primeira amostragem & Segunda amostragem \\
\hline Entrada & 0 & - & 0 & - \\
\hline Lateral esquerda & 0 & 0 & 0 & 0 \\
\hline Interm. esq. até $10 \mathrm{~m}$ & 0 & 1 & 0 & 0 \\
\hline Interm. esq. abaixo de $10 \mathrm{~m}$ & 0 & 0 & 0 & 0 \\
\hline Centro até 3,6 m & 0 & 1 & 0 & 0 \\
\hline Centro 3,6 m-8,4 m & 1 & 0 & 0 & 0 \\
\hline Centro abaixo de $8,4 \mathrm{~m}$ & 0 & 1 & 0 & 0 \\
\hline Interm. dir. até 10 m & 0 & 0 & 0 & 0 \\
\hline Interm. dir. abaixo de 10 m & 1 & 0 & 0 & 0 \\
\hline Lateral direita & 0 & 0 & 0 & 0 \\
\hline Expedição & 0,57 & & 0,85 & \\
\hline
\end{tabular}

Tabela 7. Médias de peso de mil grãos (PMG), teor de óleo (TO), acidez do óleo (AO), \% de grãos infestados (GI) e índice de insetos (II) nas amostras da expedição dos grãos nos septos resfriado e aerado

\begin{tabular}{|c|c|c|c|c|c|}
\hline \multirow{3}{*}{ Tratamentos } & \multicolumn{5}{|c|}{ Variáveis } \\
\hline & PMG & TO & AO & GI & II \\
\hline & \multicolumn{5}{|c|}{ Médias } \\
\hline Septo resfriado & $309,59 a$ & $4,06 \mathrm{a}$ & $5,8 \mathrm{a}$ & $1,8 \mathrm{a}$ & $6,06 a$ \\
\hline Septo aerado & $305,06 \mathrm{a}$ & $3,75 b$ & $6,6 \mathrm{a}$ & $4,9 \mathrm{~b}$ & $5,77 \mathrm{a}$ \\
\hline
\end{tabular}

Médias seguidas por letras minúsculas iguais na mesma coluna não diferem entre si pelo teste de Tukey a 5\% de significância

temperaturas difere consideravelmente entre as espécies e é plenamente modificada pela umidade relativa e aclimataçáo termal (Evans, 1983).

Em relação ao índice de insetos-praga, foi observado, de forma geral, que no septo aerado houve incremento significativo no número de insetos encontrados por quilograma de amostra, passando de 1,12 insetos $\mathrm{kg}^{-1}$ para 3,74 insetos $\mathrm{kg}^{-1}$, enquanto que no septo resfriado observou-se uma redução da infestação de 2,77 insetos $\mathrm{kg}^{-1}$ insetos para 2,23 insetos $\mathrm{kg}^{-1}$. Dessa forma, a temperatura nos septos influenciou a quantidade de insetos na massa de grãos nas duas amostragens realizadas. Tal resultado corrobora os de LAZZARI et al. (2006), que afirmam que o resfriamento artificial de grãos é uma ferramenta valiosa na redução da multiplicação de insetos e manutenção da qualidade e da massa de grãos armazenados.

$\mathrm{Na}$ expedição verificou-se que o resfriamento artificial não influenciou o peso de mil grãos, a acidez do óleo e o índice de insetos (Tabela 7). O produto expedito do septo aerado teve maior porcentagem de grãos infestados e menor teor de óleo. Essa relação inversa entre índice de infestação de insetos na massa de grãos e teor de óleo também foi observada por Matioli e Almeida (1979) e Souza et al. (1999).

\section{CONCLUSÕES}

A utilização do resfriamento artificial no armazenamento de grãos de milho em regiôes tropicais é eficaz na manutenção da qualidade dos grãos e no manejo de insetos e patógenos.

\section{AGRADECIMENTOS}

À Caramuru Alimentos S/A e à Universidade Federal de Viçosa pelo apoio técnico e operacional para a realização desta pesquisa.

\section{REFERÊNCIAS}

ABRAMSON, D.; HULASARE, R.K.; YORK, R.K.; WHITE, N.D.G.; JAYAS, D.S. Mycotoxins, ergosterol, and odor volatiles in durum wheat during granary storage at $16 \%$ and $20 \%$ moisture content. Journal of Stored Products Research, v.41, p.67-76, 2005. http://dx.doi.org/10.1016/j.jspr.2003.11.002

AGÊNCIA NACIONAL DE VIGILÂNCIA SANITÁRIA - ANVISA. Resoluçáo RDC no 274, de 15 do outubro de 2002 (publicada no dia 16/10/2002). Regulamento Técnico Mercosul sobre Limites Máximos de Aflatoxinas no Leite, Amendoim e Milho. Diário Oficial da República Federativa do Brasil, Brasília, DF, out. 2002.

AGÊNCIA NACIONAL DE VIGILÂNCIA SANITÁRIA - ANVISA. Resoluçáo RDC no 7, de 18 do fevereiro de 2011 (publicada no dia 09/03/2011). Dispóe sobre limites máximos tolerados (LMT) para micotoxinas em alimentos. Diário Oficial da República Federativa do Brasil, Brasília, DF, fev. 2011.

AGRICULTURAL RESEARCH ORGANIZATION - ARO. Aeration and cooling for control of stored grain insects. Disponível em: <http://www.agri.gov.il/Envir/aeration/aeration.html>. Acesso em: 17 mar. 2008.

ALVES, W.M.; FARONI, L.R.D.; QUEIROZ, D.M.; CORRÊA, P.C.; GALVÃO, J.C.C. Qualidade dos grãos de milho em função da 
umidade de colheita e da temperatura de secagem. Revista Brasileira de Engenharia Agrícola e Ambiental, v.5, p.469-474, 2001. http:// dx.doi.org/10.1590/S1415-43662001000300017

AMERICAN OIL CHEMISTS SOCIETY - AOCS. Official methods and recommended practices of the AOCS. Champaign, 1998. $1200 \mathrm{p}$.

BECKETT, S.J. Insect and mite control by manipulating temperature and moisture before and during chemical-free storage. Journal of Stored Products Research, v.47, p.284-292, 2011. http://dx.doi. org/10.1016/j.jspr.2011.08.002

BRACCINI, A.L.; PICANÇO, M. Manejo integrado de pragas do feijoeiro no armazenamento. Revista Brasileira de Armazenamento, v.20, p.37-43, 1995 .

BRASIL. Ministério da Agricultura e da Reforma Agrária. Regras para análise de sementes. Brasília: SNDA/DNDV/CLAV, 1992. 365p.

BRASIL. Resolução no 482, de 23 de setembro de 1999, republicada em 20 junho de 2000. Regulamento Técnico para Fixação de Identidade e Qualidade de óleos e gorduras vegetais. Diário Oficial da República Federativa do Brasil, Brasília, jun. 2000.

CARRERA-RODRÍGUEZ, M.; MARTÍNEZ-GONZÁLEZ, G.M.; NAVARRETE-BOLAÑOS, J.L.; BOTELLO-ÁLVAREZ, J.E.; RICOMARTÍNEZ, R.; JIMÉNEZ-ISLAS, H. Transient numerical study of the effect of ambient temperature on 2-D cereal grain storage in cylindrical silos. Journal of Stored Products Research, v.47, p.106122, 2011. http://dx.doi.org/10.1016/j.jspr.2011.01.006

DAVID MILLER, J. Fungi and mycotoxins in grain: implications for stored product research. Journal of Stored Products Research, v.31, p.1-16, 1995. http://dx.doi.org/10.1016/0022-474X(94)00039-V

DHINGRA, O.; SINCLAIR, J.B. Basic plant pathology methods. Nova Iorque: CRC Press, 1996. $434 \mathrm{p}$.

DOWDY, A.K.; McGAUGHEY, H. Stored-product insect activity outside of grain masses in commercial grain elevators in the midwestern United States. Journal of Stored Products Research, v.34, p.129140, 1998. http://dx.doi.org/10.1016/S0022-474X(97)00057-X

DRISCOLL, R.; LONGSTAFF, B.C.; BECKETT, S. Prediction of insect populations in grain storage. Journal of Stored Products Research, v.36, p.131-151, 2000. http://dx.doi.org/10.1016/S0022474X(99)00032-6

ELIAS, M.C. Armazenamento de grãos em pequenas e médias escalas. Pelotas: Editora da UFPEL, 2002. 218p.

ELIOPOULOS, P.A.; PRASODIMOU, G.Z.; POULIOU, A.V. Time -mortality relationships of larvae and adults of grain beetles exposed to extreme cold. Crop Protection, v.30, p.1097-1102, 2011. http:// dx.doi.org/10.1016/j.cropro.2011.04.017

EVANS, D.E. The influence of relative humidity and thermal acclimation on the survival of adult grain beetles in cooled grain. Journal of Stored Products Research, v.19, p.173-180, 1983. http:// dx.doi.org/10.1016/0022-474X(83)90005-X

FIELDS, P.; KORUNIC, Z. The effect of grain moisture content and temperature on the efficacy of diatomaceous earths from different geographical locations against stored-product beetles. Journal of Stored Products Research, v.36, p.1-13, 2000. http://dx.doi.org/10.1016/ S0022-474X(99)00021-1
FONTES, L.S.; FILHO, A.J.A.; ARTHUR, V. Danos causados por S. oryzae (Linné, 1763) e S. zeamais Motschulsky, 1885 (Coleoptera: Curculionidae) em cultivares de arroz (Oryza sativa L.). Arquivos do Instituto Biológico, v.70, p.303-307, 2003.

FOOD AND AGRICULTURE ORGANIZATION OF THE UNITED NATIONS - FAO. FAOSTAT. Data Base Results. Disponível em: <http://faostat.fao.org/site/339/default.aspx>. Acesso em: 01 jan. 2013.

GALLO, D.; NAKANO, O.; SILVEIRA NETO, S.; CARVALHO, R.P.L.; BATISTA, G.C.; BERTI FILHO, E.; PARRA, J.R.P.; ZUCCHI, R.A.; ALVES, S.B.; VENDRAMIN, J.D.; MARCHINI, L.C.; LOPES, J.R.S.; OMOTO, C. Entomologia Agrícola. Piracicaba: FEALQ, 2002. 920 p.

GARCIA, M.J.D.M.; FERREIRA, W.A.; BIAGGIONI, A.M. Desenvolvimento de insetos em milho armazenado em sistema vedado. Arquivos do Instituto Biológico, v.67, p.63-75, 2000.

GREGORI, R.; MERIGGI, P.; PIETRI, A.; FORMENTI, S.; BACCARINI, G.; BATTILANI, P. Dynamics of fungi and related mycotoxins during cereal storage in silo bags. Food Control, v.30, p.280-287, 2013. http://dx.doi.org/10.1016/j.foodcont.2012.06.033

HERRON, G.A.; CLIFT, A.D.; WHITE, G.G.; GREENING, H.G. Relationships between insecticide use, grain hygiene and insecticide resistance in Oryzaepldus surinamensis (L.) (Coleoptera:Silvanidae) on grain-producing farms. Journal Stored Products Research, v.32, p.131-136, 1996. http://dx.doi.org/10.1016/0022-474X(96)00007-0

JIA, C.; SUN, D.-W.; CAO, C. Computer simulation of temperature changes in a wheat storage bin. Journal of Stored Products Research, v.37, p.165-177, 2001. http://dx.doi.org/10.1016/S0022-474X(00)00017-5

KLICH, M.A. Aspergillus flavus: the major producer of aflatoxin. Molecular Plant Pathology, v.8, p.713-722, 2007. PMid:20507532. http://dx.doi.org/10.1111/j.1364-3703.2007.00436.x

LASSERAN, J.C. Aeração de grãos. Viçosa: Centro Nacional de Treinamento em Armazenagem, 1981. 128 p.

LAZZARI, S.M.N.; KARKLE, A.F.; LAZZARI, F. A. Resfriamento artificial para controle de Coleoptera em arroz armazenado em silo metálico. Revista Brasileira de Entomologia, v.50, p.293-296, 2006. http://dx.doi.org/10.1590/S0085-56262006000200012

LIU, Z.; GAO, J.; YU, J. Aflatoxins in stored maize and rice grains in Liaoning Province, China. Journal of Stored Products Research, v.42, p.468-479, 2006. http://dx.doi.org/10.1016/j.jspr.2005.09.003

LONGSTAFF, B.C. Decision tools for grain storage pest management. Journal of Stored Products Research, v.33, p.99-114, 1997. http:// dx.doi.org/10.1016/S0022-474X(96)00034-3

LUKOW, O.M.; WHITE, N.D.G.; SINHA, R.N. Influence of ambient storage conditions on the breadmaking quality of two hard red spring wheats. Journal of Stored Products Research, v.51, p.279-289, 1995. http://dx.doi.org/10.1016/0022-474X(95)00027-5

MARKS, B.P.; STROSHINE, R.L. Effects of previous storage history, hybrid, and drying method on the storability of maize grain (corn). Journal of Stored Products Research, v.31, p.343-354, 1995. http:// dx.doi.org/10.1016/0022-474X(95)00020-8 
MATIOLI, J.C.; ALMEIDA, A.A. Alteraçóes nas características dos grãos de milho causadas pela infestação de Sitophilus orizae. Revista Brasileira de Armazenamento, v.4, p.47-57, 1979.

NAKAKITA, H.; IKENAGA, H. Action of low temperature on physiology of Sitophilus zeamais Motschulsky and Sitophilus oryzae (L.) (Coleoptera: Curculionidae) in rice storage. Journal of Stored Products Research, v.33, p.31-38, 1997. http://dx.doi.org/10.1016/ S0022-474X(96)00022-7

NAVARRO, S.; NOYES, R. The mechanics and physics of modern grain aeration management. New York: CRC Press, 2002. 647 p.

NAVARRO, S.; NOMES, R.; JAYAS, D.S. Stored grain ecosystem and heat, and moisture transfer in grain bulks. In.: NAVARRO, S.; NOYES, R. The mechanics and physics of modern grain aeration management. New York: CRC Press. 2002. p.35-78.

PUZZI, D. Abastecimento e armazenamento de grãos. Campinas: ICEA, 2000. $601 \mathrm{p}$.

RAJARAMMANNA, R.; JAYAS, D.S.; WHITE, N.D.G. Comparison of deterioration of rye under two different storage regimes. Journal of Stored Products Research, v.46, p.87-92, 2010. http://dx.doi. org/10.1016/j.jspr.2009.10.005

SANTOS, J.P. Métodos preventivos de controle de pragas de grãos armazenados. In: LORINE, I.; MIIKE, L. H.; SCUSSEL,V.M. (Ed.). Armazenagem de grãos. Campinas: Instituto Bio Geneziz, 2002. cap. 3.3, p.157-174.

SCUSSEL, V. M. Fatores que favorecem o desenvolvimento de fungos e produção de toxinas. In: LORINE. I.; MIIKE, L.H.; SCUSSEL,V.M.
(Ed.). Armazenagem de grãos. Campinas: Instituto Bio Geneziz, 2002. cap. 9.3, p.739-756.

SOUZA, A.C.V.; LOPES, D.C.; DONZELE, J.L.; SANTOS, J.P.; OLIVEIRA, R.F.M.; OLIVEIRA, V.A.C.; FARIA, N.B.; APOLONIO, R.L. Valores de energia digestível metabolizável e do coeficiente de digestibilidade dos nutrientes do milho em diferentes níveis de carunchamento. Sete Lagoas: EMBRAPA/CNPMS, 1999. Relatório técnico anual do Centro Nacional de Pesquisa de Milho e Sorgo 1999.

SUN, D.W.; WOODS, J.L. Deep-bed simulation of the cooling of stored grain with ambient air: a test bed for ventilation control strategies. Journal of Stored Products Research, v.33, p.299-312, 1997. http://dx.doi.org/10.1016/S0022-474X(97)00010-6

VOLK, M.B.S.; AFONSO, A.D.L. Viabilidade técnica e econômica da utilizaçáo do equipamento de ar refrigerado em trigo armazenado. Revista Caatinga, v.22, p.9-17, 2009.

UDOH, J.M.; CARDWELL, K.F.; IKOTUN, T. Storage structures and aflatoxin content of maize in five agroecological zones of Nigeria. Journal of Stored Products Research, v.36, p.187-201, 2000. http:// dx.doi.org/10.1016/S0022-474X(99)00042-9

VOWOTOR, K.A.; BOSQUE-PEREZ, N.A.; AYERTEYZ, J.N. Effect of maize variety and storage form on the development of the maize weevil, Sitophilus zeamais Motschulsky. Journal of Stored Products Research, v.31, p.29-36, 2000. http://dx.doi.org/10.1016/0022474X(94)00038-U

WHITE, N.D.G. A multidisciplinary approach to stored-grain research. Journal of Stored Products Research, v.28, p.127-137, 1992. http:// dx.doi.org/10.1016/0022-474X(92)90020-Q 